In spite of chemical differences, lincomycin has been shown to have an antibacterial activity similar to that of the macrolides, including partial cross-resistance.

Pristinamycin has an activity that might have been predicted from its chemical similarity to ostreogrycin.

\section{REFERENCES}

Arai, M., Fukahara, S., Nakamura, S., Yonehara, H., and Umezawa, H. (1958). F. Antibiot. (Tokyo), Ser. A, 11, 14.

Benazet, F., and numerous others (1962). Sem. thér., 38, 13, 19, 25, 49, $57,68,71$

Celmer, W. D. (1955-6). Antibiot. Ann., p. 452. de Somer, P., and van Dijck, P. (1955). Antibiot. and Chemother., 5, 632

Garrod, L. P. (1957). Brit. med. 7., 2, 57.

and Waterworth, P. M. (1956). Ibid., 2, 61.

Herr, R. R., and Bergy, M. E. (1962). Antimicrobial Ag. Chemother., p. 560 .

Hobbs, D. C., and Celmer, W. D. (1959). Fed. Proc., 18, 246.

Jones, W. F., Nichols, R. L., and Finland, M. (1956). Proc. Soc. exp. Biol. (N.Y.), 93, 388.

Lewis, C. Clapp, H. W., and Grady, J. E. (1962). Antimicrobial Ag. Chemother., p. 570.

Mason, D. J., Dietz, A., and Deboer, C. (1962). Ibid., p. 554.

van Dick, P., Vanderhaeghe, H., and de Somer, P. (1957). Antibiot. and Chemother., 7, 625 .

Verwey, W. F., West, M. K., and Miller, A. K. (1958). Ibid., 8, 500.

Waterworth, P. M. (1950). Antibiot. and Chemother., 10, 101.

Yamaguchi, H. (1961). F. Antibiot. (Tokyo), Ser. A, 14, 313.

\title{
Identification of Histamine Metabolite 1-methyl,4-imidazole Acetic Acid in Human Urine and its Absence in Status Asthmaticus
}

\author{
JAMES W. KERR,* M.B., M.R.C.P., M.R.C.P.G
}

Brit. med. F., 1964, 2, 606-608

Since the identification of histamine by Barger \& Dale (1910) and the appreciation of its pharmacological activity (Dale and Laidlaw, 1911) there has been abundant evidence that histamine release is concerned in the reactions of hypersensitivity. The introduction of antihistamine drugs (Halpern, 1942) and the demonstration of their value in the treatment of hay-fever and urticaria appeared to confirm the part played by histamine release in these conditions. In sharp contrast is their ineffectiveness in the treatment of bronchial asthma.

The evidence that histamine metabolism is disturbed in an attack of bronchial asthma is conflicting and confused. Rose, Rusted, and Fownes (1950) measured histamine levels in arterial and pulmonary mixed venous blood of asthmatic patients during an induced attack of asthma. They reported arterial levels of free histamine higher than the pulmonary. mixed venous levels during the attack. Both were higher than in non-asthmatic control patients. Human bronchial rings from a case of grasspollen asthma have been shown to constrict when challenged with pollen antigen, with the liberation of histamine into the organ bath (Schild, Hawkins, Mongar, and Herxheimer, 1951). On the other hand, Mitchell, Logan, Peters, and Henderson.(1954), in a careful study of asthmatic children, showed that in intervals between attacks the free-histamine output in the urine was within the normal range and during acute attacks of asthma the concentration of free histamine in the urine tended to decrease.

Karjala, Turnquest, and Schayer (1956), Schayer and Karjala (1956), and Shayer (1959) have studied the metabolism of physiological quantities of injected ${ }^{14} \mathrm{C}$ ring labelled histamine in animals and man. Methylation of the imidazole ring $\mathrm{N}$ is a major route of metabolism (Fig. 1). The methyl histamine formed * Senior Medical Registrar, Medical Research Council
Atheroma Research Unit, Western Infirmary, Glasgow. is biologically much less active than histamine and is largely oxidized to 1-methyl,4-imidazole acetic acid (Schayer and Kariala, 1956). When minute amounts of ring labelled ${ }^{14} \mathrm{C}$ histamine are injected intradermally in man, over $80 \%$ of the radioactivity can be recovered in the urine within six hours. Urine analysis shows that 1-methyl,4-imidazole acetic acid is
FIG. 1.-Histamine is formed by the decarboxylation of L-histidine, and 1-methyl,4-imidazole acetic acid is a specific metabolite of histamine metabolism. The riboside of imidazole acetic acid can be formed by the transamination of $\mathrm{L}$-histidine or via histamine.

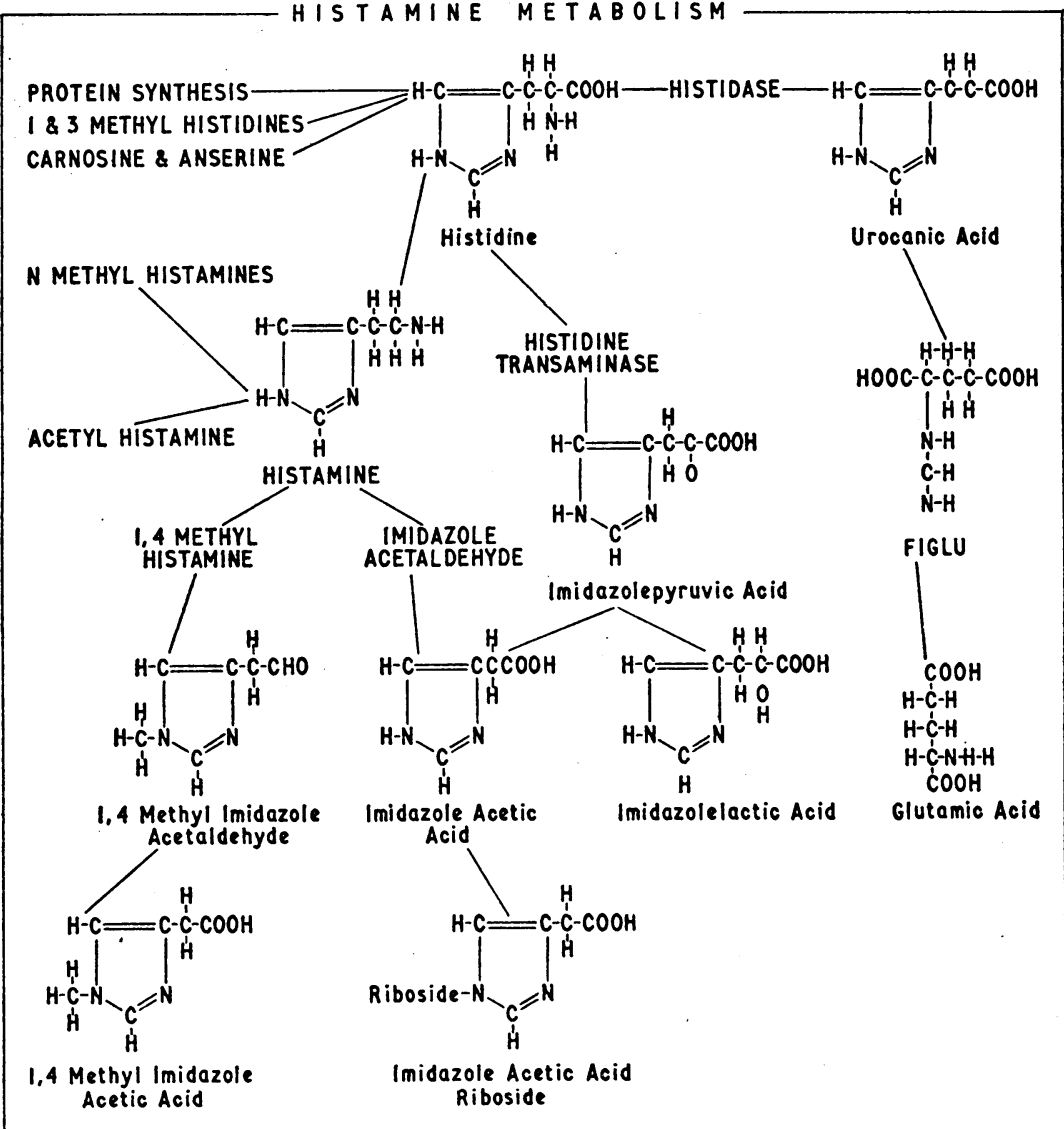


the principal metabolite, and accounts for at least $40 \%$ of the recovered radioactivity. The riboside of imidazole acetic acid and methyl histamine account for most of the remaining activity ; only $2 \%$ of the original radioactivity is recovered as histamine (Schayer and Cooper, 1956).

In the present paper 1-methyl,4-imidazole acetic acid has been identified on paper chromatograms prepared from urine extracts of normal adults. This identification was made by comparison with pure 1-methyl,4-imidazole acetic acid and isotopic 1-methyl,4-imidazole acetic acid extracted from guinea-pig urine and by comparison of the ultra-violet absorption spectra of pure 1-methyl,4-imidazole acetic acid with the unknown substance eluted from chromatograms of human urine. The absence of 1-methyl,4-imidazole acetic acid from the urine extracts of patients admitted in status asthmaticus and the effect of steroid therapy is also reported.

\section{Materials and Methods}

Isotopic Histamine.-Histamine labelled with ${ }^{14} \mathrm{C}$ in the 2 position of the imidazole ring, specific activity $39.4 \mu \mathrm{c} / \mathrm{mg}$., was obtained from the Radiochemical Centre, Amersham.

Injection of ${ }^{14} \mathrm{C}$ Histamine into Guinea-pigs.-Three guineapigs, each weighing $350 \mathrm{~g}$., received a subcutaneous injection of ${ }^{14} \mathrm{C}$ histamine $(50 \mu \mathrm{g} . / \mathrm{kg}$.). The 24 -hour urine from the guinea-pigs was pooled, acidified with $2 \mathrm{~N} \mathrm{HCl}$, and evaporated and one-third total volume was evaporated to dryness in vacuo at $45^{\circ} \mathrm{C}$. The residue was extracted in $100 \mathrm{ml}$. of boiling methanol for three hours, evaporated to dryness, and dissolved in $10 \mathrm{ml}$. of water. The $10-\mathrm{ml}$. extract was added to a $40 \times 1$ $\mathrm{cm}$. Dowex $1 \times 8$ acetate column (100-200 mesh) and washed with $40 \mathrm{ml}$. of water. A gradient elution of the column was carried out with $0.75 \mathrm{~N}$ acetic acid dripping into $200 \mathrm{ml}$. of water and the eluate collected in $5-\mathrm{ml}$. aliquots, which after a preliminary ether extraction to remove most phenols and hydroxyindoles were evaporated to dryness and made up to $1 \mathrm{ml}$. with water. This solution was used for spotting the paper chromatograms.

Paper Chromatography.-Ascending chromatograms were run on Whatman No. 4 paper in four solvents:

(1) $n$-Butanol/acetic acid glacial/water in the ratio $12: 3: 5$ (Bu.A.).

(2) $n$-Butanol/pyridine/water in the ratio $1: 1: 1$ (Bu.P.).

(3) iso-Propanol/ammonia 880 / water in the ratio $20: 1: 2$ (iPr.Am.).

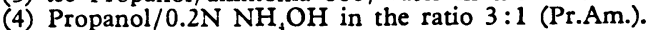

The radioactive guinea-pig urine preparation was used, $5-\mu l$. spots being applied to the paper. In addition, $40 \mu \mathrm{g}$. of nonisotopic 1-methyl,4-imidazole acetic acid was run by itself and together with $5-\mu l$. spots of the radioactive urine preparation. These chromatograms were run in solvents Pr.Am. and Bu.P., the solvent flow being carried out overnight.

The paper chromatogram was dried, and after exposure to $x$-ray film for three weeks the film was developed and the paper dipped in p-nitroaniline stain (Smith, 1960). Paper chromatograms were prepared spotting $40 \mu \mathrm{l}$. of each $5-\mathrm{ml}$. aliquot from the controls and patients in status asthmaticus. Control papers were run spotting $200 \mu \mathrm{g}$. in $20 \mu \mathrm{l}$. of $1-$ methyl,4-imidazole acetic acid. In addition, papers were prepared with $20 \mu \mathrm{l}$. of the unknown urine extract and 10 $\mu 1$. of 1-methyl,4-imidazole acetic acid applied at one spot. The chromatograms were run overnight in the solvents and thoroughly dried before dipping in p-nitroaniline stain.

Identification by Ultraviolet Absorption Spectra.Ascending chromatograms were run in duplicate, spotting $40 \mu \mathrm{l}$. of the first $5-\mathrm{ml}$. aliquot from the column pre-
FIG. 2.-Autoradiograms from the urine of guinea-pigs 1 and 2 run in propanol-ammonia to show the three Fig. 2.- Autoradiograms from the urine of guinea-pigs 1 and 2 run in propanol-ammonia to show the three
radioactive peaks. The middle peak is ${ }^{14} \mathrm{C} 1$-methyl,4-imidazole acetic acid. $\mathrm{O}=\mathrm{Origin}$. Arrow shows direction of solvent flow.

to dryness. The urine was extracted in $25 \mathrm{ml}$. of boiling methanol for two hours. After cooling, the methanol extract was filtered, the filtrate evaporated to dryness, and the residue dissolved in $1 \mathrm{ml}$. of water. This solution was used for spotting paper chromatograms.

Preparation of Urine from Controls and Patients Admitted in Status Asthmaticus.-Twenty-four-hour collections of urine were made from seven healthy adults with no history of allergic disease and on a free diet. Similar urine collections were made from seven patients in status asthmaticus and two patients with eosinophilia, one with pericarditis and the other with tuberculous adenitis. The patients in status asthmaticus had all complained of asthma for several years, and all except one had a history of infantile eczema. They were in the age range 8-30 years and an eosinophilia was present in each case, the lowest count before steroid therapy being 700 cells/c.mm. During the initial 24 hours in hospital drug therapy was kept to a minimum and steroid therapy was avoided. In the second 24 hours in hospital the patients received 80 units of corticotrophin gel and a further 24-hour urine collection was made. The urine was collected in containers with $5 \mathrm{ml}$. of $2 \mathrm{~N} \mathrm{HCl}$ and stored at $-20^{\circ} \mathrm{C}$. until required. The urine was filtered pared from control subjects and two similar papers spotted with $400 \mu \mathrm{g}$. in $40 \mu \mathrm{l}$. of 1 -methyl,4-imidazole acetic acid. One urinary extract and one 1-methyl,4-imidazole acetic acid paper were stained and used to locate the unknown and the 1-methyl,4-imidazole acetic acid respectively in the unstained papers. These areas were marked, cut out, and eluted overnight with $90 \%$ ethanol. The ethanol was evaporated to dryness and the residue redissolved in $25 \mathrm{ml}$. of water and the $\mathrm{pH}$ adjusted to 4 . The ultra-violet spectra of the material from both papers were measured in a Unicam S.P. 500 spectrophotometer.

\section{Results}

The autoradiograms from the guinea-pig urine each showed three radioactive peaks (Fig. 2):

$\begin{array}{llcccccc} & & & \text { Peak I } & & \text { Peak II } & & \text { Peak III } \\ \text { Rf in Bu.P. } & \ldots & \ldots & 0.29 & \ldots & 0.45 & \ldots & 0.62 \\ \text { Rf in Pr.Am. } & & \ldots & 0.21 & \ldots & 0.43 & \ldots & 0.69\end{array}$

Peak II in Bu.P. and Pr.Am. corresponded to the $R f$ of non-isotopic 1-methyl,4-imidazole acetic acid run in the 
identical solvent system. Further, when the radioactive urine extract and 1-methyl,4-imidazole acetic acid were applied as one spot the second radioactive peak coincided with the red spot of 1-methyl,4-imidazole acetic acid stained with $p$ nitroaniline.

Paper chromatograms prepared from the first 5-ml. aliquot of eluant of control subjects and of the two patients with eosinophilia but no history of asthma showed a red spot when stained with $p$-nitroaniline. The $\mathrm{Rf}$ of this spot in Bu.A.= 0.35 , in Bu.P. $=0.46$, and in $\operatorname{Pr} . A m .=0.25$, and identical staining and $\mathrm{Rfs}$ were obtained from 1-methyl,4-imidazole acetic acid run on control papers. In addition, when paper chromatograms were run with the urinary extract and the 1methyl,4-imidazole acetic acid was applied to the same spot on the paper, the known and unknown ran as one p-nitroanilinestaining spot. The two patients with eosinophilia (but no asthma) appeared to have at least twice the output of 1-methyl, 4-imidazole acetic acid as compared with the non-asthmatic controls.

The ultra-violet absorption of the unknown compound was identical with that of 1-methyl,4-imidazole acetic acid, the absorption maximum being $211 \mathrm{~m} \mu$ (Fig. 3).

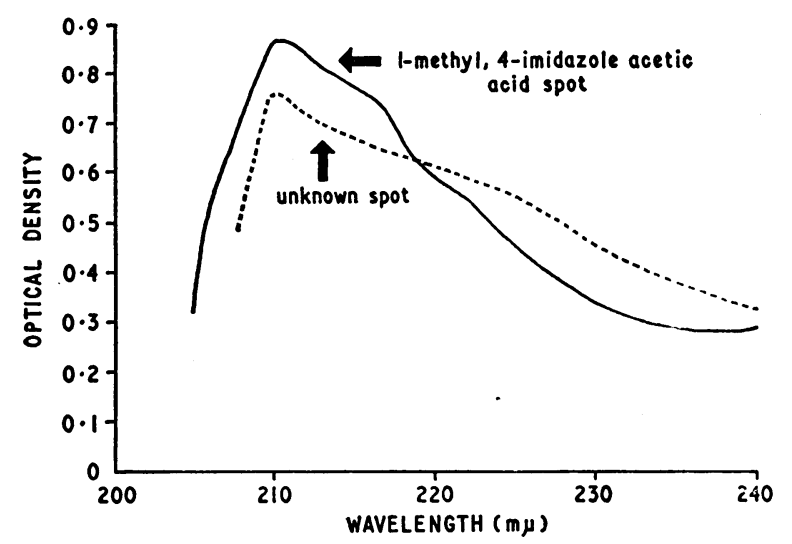

FIG. 3.-Comparison of the ultra-violet spectra of 1-methyl,4imidazole acetic acid and unknown spot eluted from paper

In the six patients admitted in status asthmaticus no 1methyl,4-imidazole acetic acid could be identified in the first 24-hour collection of urine. Paper chromatograms were prepared in an identical way from the second 24-hour urine collection while the patient was having corticotrophin therapy. In these chromatograms 1-methyl,4-imidazole acetic acid could be identified.

\section{Discussion}

In this paper the histamine metabolite 1-methyl,4-imidazole acetic acid has been identified in human urine. The isotopic studies with physiological doses of ring labelled ${ }^{14} \mathrm{C}$ histamine (Schayer and Cooper, 1956) have shown that ring methylation is the principal route for the human metabolism of histamine (Fig. 1). Further, Brown, Tomchick, and Axelrod (1959) have shown that the methylating enzyme is specific for histamine, which suggests that 1-methyl,4-imidazole acetic acid in the urine is a measure of histamine metabolism. The increased amounts of 1-methyl,4-imidazole acetic acid found in the two patients with eosinophilia but no history of bronchial asthma indicates that these patients have an increase in histamine metabolism, and contrasts with the failure to identify significant quantities of 1-methyl,4-imidazole acetic acid in the urine of patients admitted in status asthmaticus and with an eosinophilia. This, with the presence of urocanic acid in the urine of patients admitted in status asthmaticus (Kerr, 1963), is consistent with a block in metabolism of histamine ; the presence of urocanic acid being due to a physiological Lhistidine overload (Fig. 1) (Whitehead, 1962). As 1-methyl histamine is biologically almost inactive the block is most likely to be due to a failure of ring methylation, and suggests that histamine is not being made available for methylation during an asthmatic attack. This is supported by the observation of Mitchell et al. (1954) that even less free histamine than normal is present in the urine in an attack of asthma. Further, Rose et al. (1950) reported one case of asthma in which lobectomy was carried out and the amount of histamine in the lung was five times that in non-asthmatic lung material used as control. These authors suggested that in an asthmatic attack there was lowered " histaminase" activity in the lung.

Lilja, Lindell, and Saldeen (1960) have shown that human lung when incubated with ${ }^{14} \mathrm{C}$ histidine forms ${ }^{14} \mathrm{C}$ histamine but no ${ }^{14} \mathrm{C}$ histamine metabolites ; on the other hand, the same lung incubated with ${ }^{14} \mathrm{C}$ histamine forms the histamine metabolites ${ }^{14} \mathrm{C} \quad 1$-methyl,4-histamine and ${ }^{14} \mathrm{C}$ 1-methyl,4imidazole acetic acid. It appears that the newly formed ${ }^{14} \mathrm{C}$ histamine is not immediately available for methylation. The physiological mechanism whereby histamine is made available for methylation requires further study.

Another possibility is a deficiency of the histamine methylating enzyme, and here we would expect evidence of overloading the alternative non-specific pathway of histamine metabolism to the riboside of imidazole acetic acid (Fig. 1).

One of the effects of corticotrophin therapy is as a histamine liberator (Telford and West, 1963). In the asthmatic subjects reported here 1-methyl,4-imidazole acetic acid could be identified in the urine while the patient was on corticosteroid therapy, but only occasionally in greater quantity than in the controls.

The absence of 1-methyl,4-imidazole acetic acid in status asthmaticus appears to confirm that abnormal histamine metabolism is a factor in an attack of bronchial asthma.

\section{Summary}

The histamine metabolite 1-methyl,4-imidazole acetic acid has been extracted and identified in human urine. The identification is by comparison with pure and isotopic 1-methyl,4imidazole acetic acid on paper chromatograms and by comparison of the ultra-violet absorption spectra. In patients admitted in status asthmaticus with eosinophilia no 1-methyl, 4-imidazole acetic acid could be identified in the urine extracts before steroid therapy. In contrast, chromatograms prepared from the urine collection of controls and of patients with eosinophilia but no asthma showed 1-methyl,4-imidazole acetic acid. The significance of this observation is discussed, and it is suggested that in status asthmaticus histamine is not being made available for methylation.

I wish to thank Dr. B. Bronte-Stewart for assistance in the preparation of this paper, and Mr. Robert Rae for technical assistance.

\section{REFERENCES}

Barger, G., and Dale, H. H. (1910). F. Physiol. (Lond.), 40, 38. Brown, D.' D., Tomchick, R., and Axelrod, J. (1959). F. biol. Chem., 234, 2948.

Dale, H. H., and Laidlaw, P. P. (1911). F. Physiol. (Lond.), 41, 318.

Halpern, B. N. (1942). Arch. int. Pharmacodyn., 68, 339.

Karjala, S. A., Turnquest, B., and Schayer, R. W. (1956). F. biol. Chem.,

219, 9 . (1963). Lancet, 2, 709.

Kerr, J. W. (1963). Lancet, 2, 709. .

Mitchell, R. G., Logan, G. B., Peters, G. A., and Henderson, L. L. (1954). Ibid., 25, 504 .

Rose, B., Rusted, I., and Fownes, J. A. (1950). 7. clin. Invest., 29, 1113. Schayer, R. W. (1959). Physiol. Rev., 39, 116.

- and Cooper, J. A. D. (1956). F. appl. Physiol., 9, 481.

Schild, H. O., Hawkins, D. F., Mongar, J. L., Herxheimer, H. (1951) Lancet, i, 376 .

Smith, I. (1960). Chromatographic and Electrophoretic Techniques, vol. 1. Heinemann, London.

Telford, J. M., and West, G. B. (1963). Int. Arch. Allergy, 23, 29.

Whitehead, R. G. (1962). Lancet, 2, 203. 